\title{
The planning of business processes in an uncertain environment on oligopolistic markets
}

\author{
Alexander Aleksakhin ${ }^{1 *}$, Ivan Zaytsev ${ }^{1}$, Evgeniya Eliseeva ${ }^{1}$, Angelina Petergova ${ }^{2}$, and \\ Luydmila Kostygova ${ }^{1}$ \\ ${ }^{1}$ College of Economics \& Industrial Management, NUST MISIS, Russia, 119049, Moscow \\ ${ }^{2}$ Branch Economy Department, Moscow Polytechnic University, Russia, 107023, Moscow
}

\begin{abstract}
In today markets conditions, the company independently determines their goals and tasks, and chooses the most effective management methods depending on current economic situation. For achieving a stable position in the market, the company needs to improve approaches related to strategic management, in particular, to develop a competitive strategy for providing resources using special economic mechanisms. One of the areas for improving the strategy can be the application of a scientifically based management system to ensure the process of rational procurement of raw materials, which will enable detailed planning of the business processes of the enterprise. Managing the process of rational procurement of raw materials of the necessary components is expedient to implement, using elements of game theory. The models described in this paper allow us to formalize the behavior of companies on the oligopolistic market. It helps to develop recommendations for making strategic decisions for providing raw materials with the necessary components in conditions of uncertainty.
\end{abstract}

\section{The strategy of resources planning}

Many authors in their papers describe undefined conditions in some business [1-7] and in different regions [11-12]. For achieving a stable position on the market, a company needs to improve approaches related to strategic management, particularly, to develop a competitive strategy for providing resources using specially created economic mechanisms. One of the areas for improving the strategy can be the application of a scientifically based management system to provide the process of rational purchase of raw materials, which will enable detailed planning of the business processes of the enterprise. Managing the process of rational procurement of raw materials of the necessary components is expedient to implement, using elements of game theory.

The game is a mathematical model of the conflict situation. The model of people's behavior in the game form can be used when several companies are trying to gain the most advantageous place in a competitive market, or, for instance, when several persons (or companies) want to divide a limited amount of product among each other as everyone want to get as much as possible. The game theory is the mathematical theory of decision-making

\footnotetext{
* Corresponding author: alexakhin@mail.ru
} 
in conflict situations [15]. Players in conflict economic situations modeled as a game can be industrial and non-productive firms, banks, individuals and other economic agents. For games, the result is uncertain. Uncertainty is of strategic origin: the player does not know what kind or mode of action his opponent holds, that is, the uncertainty comes from another person. The corresponding games are called strategic games.

In Russia, there are more than 100 companies that have the registration certificate of the State Assay Chamber of the Russian Federation for the right to collect and process secondary raw materials containing precious metals. The largest of them, capable of processing large amounts of raw materials, include the following: JSC Kirovograd Copper Smelting Plant; JSC «Prioksky plant of non-ferrous metals»; JSC «Krasnoyarsk Plant of Nonferrous Metals», JSC «Shchelkovo Plant»; JSC «Mosexpo-metal». Let's look at the application of the game theory in a conflict situation, when several companies of the secondary metallurgy of precious metals are interested in purchasing a pack of raw materials (electronic scrap) that has arrived on the market. At present, throughout the world, including in Russia, the amount of electronic scrap, suitable for secondary processing for the purpose of extracting precious and non-ferrous metals, is growing at a fast pace. This is due to the technical re-equipment of industries, the modernization of the fleet of computers and other electronic devices at enterprises, organizations and military units. The extraction of precious metals from recycled materials is part of the problem of using returnable resources. The formed wastes, on the one hand, cause great damage to the environment; on the other hand, they represent the most valuable resources, in terms of the content of useful components hundreds and thousands of times superior to natural sources. The rise in gold prices observed in recent years and the consistently high prices of other precious metals such as silver, platinum, palladium make it economically advantageous to process electronic scrap.

The competitive environment is fairly homogeneous. The aforementioned plants have the technical capabilities to process a wide range of raw materials, except for computer equipment of domestic and foreign production (personal computers, workstations, servers, general-purpose computers, peripheral facilities), electronic, radio electronic and electrical equipment, Ashes of porcelain manufactures, sludge of gold electrolysis. The range of services and price lists for all plants are approximately the same. Since enterprises capable of processing large quantities of any raw materials in the secondary processing of precious metals are few, and each of them, having a certain influence, is forced to reckon with the presence and behavior of other counterparties, the secondary metallurgy market belongs to the oligopoly. The behavior of firms in the oligopolistic secondary metals market of precious metals is strategic, as each of them is compelled to take into account the possible retaliatory actions of competitors. The strategic interaction of firms under oligopoly conditions takes place in two main forms: in the form of non-cooperative interaction (when firms compete with each other and conduct more independent policy on the market) and in the form of cooperative behavior (when firms agree on joint actions and can act on the market "United front"). In the market for the purchase of electronic scrap as raw materials for processing, the interaction of enterprises occurs as a non-cooperative interaction: if a large batch of electronic wastes enters the market, then each firm is interested in obtaining it, and if one plant buys a particular lot, the other is deprived of this opportunity. Justification of recommendations for carrying out its policy on attracting suppliers is proposed to be obtained with the help of game theory. The ability of an enterprise to determine its strategy can be achieved through the use of models of non-cooperative behavior, namely, models of antagonistic games. The antagonism of interests creates conflict, while the coincidence of interests reduces the game to pure coordination, accordingly, such situations can be reflected by non-cooperative or cooperative games. In a conflict situation, decisions are made not by one individual but by several participants, and 
the winning function of each depends not only on its strategy but also on the decisions of other participants. If the players are two, and their interests are opposite, then the game is called antagonistic. The basic concepts of the theory of antagonistic games were introduced by E. Borel $[16,17]$.

\section{Description of the methodology}

We consider a model of a finite (in terms of the number of players and their strategies) games with complete information, in which two parties with opposite interests participate. This game is usually called the ultimate game of two persons with zero-sum or antagonistic. At the disposal of each player, there are many strategies. The antagonistic game is given by the aggregate (1)

$$
G=(X, Y, F(x, y))
$$

where

$X=\{x 1, x 2, \ldots\}-$ set of strategies for the first player,

$Y=\{y 1, y 2, \ldots\}-$ set of strategies for the second player.

A strategy is understood as a set of rules (principles) that determine the choice of an option for each personnel move of the player, depending on the situation. Player 1 chooses strategy $x$ from $X$, player 2 chooses strategy $y$ from $Y$. The normal form of the game implies that each player chooses his strategy independently, not knowing the choice of partner. $F(x, y)$ - the payoff function of the first player, defined on $X$ and $Y$. In a zero-sum game, the first player's $F(x, y)$ win is the loss for the second player. The first player's goal is to increase his winnings $F(x, y)$.

The strategic behavior of firms buying electronic scrap can be considered as a model of game dynamics when the game is repeated at certain points in time and the state of the economic environment is changing. Models of this type are constructed as an alternative to static optimality principles, such as the Nash equilibrium and dominance solution. Consider the situation on the interaction of competing enterprises in the market for the purchase of electronic scrap, when a large consignment of raw materials enters the market. This situation can be considered as a conflict, since there are several participants in this market, each of which pursues opposite goals, and the result of the event on each side depends on the actions of the competitor. It is assumed that the operation (game) is conducted against a reasonable opponent (competitor), pursuing its own goals and consciously opposing the achievement of the goal by the other participant. So, if a large consignment of raw materials comes to the market after the technical re-equipment of some large organization, then each potential processor tries to acquire it, thereby counteracting the acquisition of this party by another participant. The result of the game is victory or defeat, which in some cases can be conditionally expressed in numbers, for example $0,1 / 2,1$. The conflict situation in such a market is determined by the following features: the presence of 2 or more parties to the conflict, in this case, the enterprises-processors of electronic scrap; each participant has a set of strategies $X=\{x j\}, j=1 \ldots m$; increase or not increase the price of a certain kind of raw materials in relation to equilibrium prices. Each participant has information about the set of strategies of others, but does not know which strategy will be adopted by either of them; the effectiveness of the actions of any participant is determined using the efficiency function $\mathrm{E}$; the effectiveness of each participant's actions depends not only on his own but also on the strategies chosen by other participants. All these features are inherent in the oligopolistic market of this industry. It is believed that oligopolistic relations are antagonistic. If the effectiveness of each activity is evaluated as a function of $E_{1}$ and $E_{2}$, then $E_{1}=f(X, Y), E_{2}=f(X, Y)$, where $\mathrm{X}$ and $\mathrm{Y}$ are sets of strategies of conflicting players, 
then condition $E_{1}=-E_{2}=E$. If one of the oligopolists buys a batch of raw materials, the other loses this opportunity, so this conflict situation can be described as a zero-sum game model when one of the players wins as much as the other [18].

The development of the game in time is represented as a series of successive "moves". The moves can be conscious and random. A conscious move is a player's choice of one of the possible options for action (strategy) and making a decision about its implementation. An antagonistic game is called a matrix game if the sets of player strategies are finite: $X=$ $\left\{x_{1}, x_{2}, \ldots, x_{m}\right\}, Y=\left\{y_{1}, y_{2}, \ldots, y_{n}\right\}$. The possible variants (outcomes) of the game are reduced to a rectangular table - a payment matrix in which the lines correspond to the different strategies of the first player, the columns to the strategies of the second player, the values in the cells are called the price of the game. The element of the matrix $u_{i j}$ - player 1 win if he applies the strategy $x_{i}$, and his opponent is a strategy $y_{j}$. In the game of two persons with zero-sum, as in any other strategic game, the outcome depends on the behavior of both players. The goal of the theory of games is to develop recommendations for the different behavior of players in a conflict situation, that is, to choose the optimal strategy for each of them. To find the optimal strategy, it is necessary to analyze all possible strategies and to expect that a reasonable opponent for each of them will respond in such a way that the other player's winnings are minimal [19]. If player 1 does not know how his opponent will act, then, acting most expediently, not wishing to take risks and believing that the enemy will also act expediently, he will choose a strategy that guarantees him the greatest of the smallest wins for any opponent strategy. The preferred or cautious strategy for the first player is to select the maximum value from the minimum in each line: $\alpha=\max \min \mathrm{u}_{\mathrm{ij}}$, where $\alpha$-maximized winnings, and the corresponding strategy is maximin. If you stick to the maximin strategy, then for any behavior of the competitor the first player is guaranteed a win, in any case not less than $\alpha$. Therefore, $\alpha$ is also called the lower price of the game or abbreviated to maximin. This is the guaranteed minimum, which can be provided with the most cautious (reinsurance) strategy. In turn, player 2, acting rationally, will choose a strategy that guarantees him the smallest possible loss for any opponent's actions. It must select the minimum value from the maximum in the columns: $\beta=\min (\max (u i j)), \beta-$ minimax loss, the corresponding strategy is minimax. Adhering to the minimax strategy, the second player will lose at least $\beta ; \beta$ is called the top price of the game or the minimum. The numbers $\alpha$ and $\beta$ are respectively the maximum guaranteed payoff of the first player and the minimum guaranteed loss of the second player. They are connected by inequality: $\max \min \mathrm{u}_{\mathrm{ij}} \leq \min \max \mathrm{u}_{\mathrm{ij}}$. If the equality $\max \left(\min \left(\mathrm{u}_{\mathrm{ij}}\right)\right)=\min \left(\max \left(\mathrm{u}_{\mathrm{ij}}\right)\right)$ if the equality $=\mathrm{C}$, that is, the lower price of the game equals its upper price, then $\mathrm{C}$ is called the price of the game or the saddle point. If a strict inequality, then it is considered that the game has no price. Finding the solution of the game consists in choosing a pair of maximin and minimax strategies that are optimal since any deviation from these strategies leads to a decrease in the first player's gain and an increase in the loss of the second player compared to the game price. In an antagonistic game that has a solution, the components of the saddle point are the maximin and minimax strategies of the players and, conversely, any pair of such strategies form a saddle point [20].

For games with zero-sum, a pair of optimal strategies is a saddle point. The key characteristic of zero-sum games is the existence or absence of the price of the game. If the game has a price, then the optimal strategies exist and are defined equivalently in two ways: in isolation (as cautious strategies) and simultaneously by both players (as saddle points). However, there are two zero-sum game matrices for which $\alpha \neq \beta$, that is, the saddle point defined above is absent. The outcome of such a game is harder to define because there is no one, the so-called pure optimal strategy for any player. In such cases, it is said that there is no solution to the game in pure strategies, and they consider the socalled mixed expansion of the game, the solution of which is sought in mixed strategies. A 
mixed player strategy is a random variable whose values are pure strategies. The task of the mixed strategy of the player is to indicate the probabilities (frequencies) with which his initial (mixed) strategies are selected. It is assumed that the game is repeated many times.

For a matrix game $\mathrm{m} \times \mathrm{n}$ denote by $P=\left(p_{1}, p_{2}, \ldots, p_{m}\right)$ mixed strategy of player 1 , where $p_{1} \geq 0, p_{2} \geq 0, \ldots, p_{m} \geq 0, \quad \sum p i=1$, across $Q=\left(q_{1}, q_{2}, \ldots, q_{n}\right)$ mixed player strategy 1 , where $q_{1}$ $\geq 0, q_{2} \geq 0, \ldots, q_{n} \geq 0, \quad \sum q j=1$. Here $p_{1}, p_{2}, \ldots, p_{m}-$ the probability of using the player 1 in the mixed strategy of his pure strategies $x_{1}, x_{2}, \ldots, x_{m} ; q_{1}, q_{2}, \ldots, q_{n}$ - the probability of using the player 2 in the mixed strategy of his pure strategies $y_{1}, y_{2}, \ldots, y_{n}$. The expectation of player 1 win: $M(P, Q)=\sum \sum x_{i j} p_{i} q_{j}$. A mixed strategy that guarantees the player the greatest possible average win (or the smallest possible average loss) is called its optimal mixed strategy, and the strategies from which the optimal mixed strategy is formed are defined as profitable strategies. Let $P^{*}$ - mixed strategy player $1, Q^{*}-$ mixed strategy player 2 . The situation $\left(P^{*}, Q^{*}\right)$, with which $M\left(P, Q^{*}\right) \leq M\left(P^{*}, Q^{*}\right) \leq M\left(P^{*}, Q\right)$, the saddle point of the mixed expansion of the game, and the mathematical expectation of the gain $v=M\left(P^{*}, Q^{*}\right)$ - at the cost of the game, always $\alpha \leq v \leq \beta$.

Consider a single repetition of the game, that is, the actions of competitors in the field of pricing when purchasing one indivisible batch of raw materials. Suppose that the supplier's preferences depend only on the price offered by the enterprise - scrap recycler. In this case, the game is antagonistic, because the interests of the players - scrap buyers are opposite. Each enterprise, aware of the intention of the provider to sell a certain amount of electronic scrap, is interested in the given batch of raw materials being supplied to it, rather than to another enterprise. This game makes sense in case of players' knowledge of the actions of competitors. In the event that one of the players is aware of the prices offered by the second, he can raise his price, of course, if he has the financial means to raise the price. If the first raised the price, and the second one does not, then the "played out" consignment of raw materials is more likely to enter it. Otherwise, if the price is raised only by the $2 \mathrm{nd}$ player, the consignment of raw materials will go to it. If both buyers offer equilibrium prices, then raw materials with equal probability can get both the 1 st and 2 nd player. Let's designate as 0 the result of the game, when the plant 1 does not buy the given amount of raw materials, 1 - buys and $1 / 2$ when the given batch with equal probability can arrive both at the plant 1 and at the plant 1 .

In an antagonistic game, the principle of equilibrium is consistent with the principles of optimizing the players for their guaranteed results. If the players, that is, the enterprises that purchase raw materials, have chosen the components of the saddle point as a strategy, then each of them does not benefit from deviating from the chosen strategy. The saddle point is a formalization of the concept of equilibrium in the game. But if one of the players does not benefit from equilibrium, he will deviate from him. With reserves to increase purchasing prices, one of the enterprises can offer the seller a higher price than the competitor, thereby deviating from the optimal strategy and breaking the price equilibrium

If the prices are balanced, the supplier's preferences depend on other factors, such as the possibility of processing a large volume of electronic scrap; possibility of processing any types of electronic scrap; the magnitude of the transport tariff, the distance from the buyer to the seller; transport accessibility of the enterprise - processor, possibility to accept the cargo, arrived by the railway; the supplier's knowledge of extraction technologies used in a particular enterprise; the relations between the supplier and the processor; the speed of calculations. When considering the continuous activity of enterprises, the conflict situation is described by a game with finite sets of strategies, and the game is repeated at times $t=$ $1,2 \ldots \mathrm{n}$. Before the sale of the next batch of raw materials, the potential supplier collects information on the prices offered for this type of raw materials, on the enterprises located in the scrap collection area, or in nearby regions ready to receive this raw material, on the possibility to take scrap at a certain time, on insurance costs and On the other criteria listed 
above. If it is possible to send the goods by mail with a small amount, the seller takes into account the speed of delivery. Enterprises that are informed of the arrival of the next batch of raw materials can choose their strategies from a finite set of strategies: to offer higher purchase prices compared to competitors, or to interest the seller with other conditions.

The process of finding a solution to a game can be considered as iterative when players choose their strategies several times according to certain rules. Such a process is called the Brown's iteration process or the Brown method [2]. It consists of repeatedly playing a matrix game, in which players, according to certain rules, choose their strategies. At the first step, players randomly choose strategies, at +1 step players choose strategies as the best response to the corresponding move of the partner. If there are several best answers, then any of them is chosen. Each player has at least one optimal strategy. The decision of the game, that is, the equilibrium situation, is when the difference between the two following values becomes less than a certain number $\varepsilon$. In this case, the strategy of the first player will be maximized, and the second - minimax. In the Brown method, the limit points of sequences of strategy uses by players are optimal mixed strategies. In addition, the limit point of the iterative process sequences is the equilibrium situation of the game. If the sets of player strategies are finite, then the mixed strategy is defined as the probability distribution, i.e. the probability of choosing one strategy as a real one. The equilibrium situations in such a game are called mixed Nash equilibria. In any game with finite sets of strategies, there is a mixed Nash equilibrium [3]. If, with a cumulative approximate equilibrium of other conditions, one of the enterprises will consistently increase purchase prices, then the other should pursue the same policy, and eventually, the equilibrium will be established at a different level.

A rational approach to finding the price of a game assumes that each player forms his or her assumptions about the behavior of the rest and builds the best answer based on these assumptions. These principles of decision-making require for their implementation a full awareness of players about the conditions of the game (that is, with respect to the sets of strategies and functions for winning all participants). Players must be rational in making their own decisions and assume the same rationality from their partners. An infinite sequence of situations is called a process trajectory. Each participant chooses a pricing strategy - to raise or not raise prices - to the next step, based on the history that has developed by this period. The strategic decisions made today depend on the previous games or at least on the initial position. This behavior is called adaptive, its meaning is that the player predicts the probability of implementing partner strategies based on the background, and maximizes his own winnings based on such a forecast. In this case, the adaptive process converges to the equilibrium situation.

The considered models of single and multiple repetitions of the game assumed the same level of awareness of players about the actions of competitors. In the oligopolistic market for the purchase of electronic scrap as raw materials for subsequent processing to extract gold and other valuable components, an asymmetric distribution of information naturally arises. Such a situation is described by the model "behavior like leader-led in the game of two persons." Each player, having received information about the strategy of another player, forms his best answer. The best answer for each player is to maximize your winnings. But at the same time, one of the players is the market leader and has information about its winning function (the result of applying its strategy) and about the function of winning a competitor. This information he uses to predict the reaction of the second participant. The second player (slave) perceives the strategy of the first player as given exogenously and maximizes his own win, believing that the strategy of the first player is fixed. Thus, player 1, having the first move and foreseeing that player 2 uses one of the best answers to the behavior of the 1st, will find the optimal solution. This situation is called the 
Stackelberg equilibrium. The use of the Stackelberg balance requires cooperation from players, which is not always possible.

In this situation, one of the firms is stronger than the rest and has the opportunity to dictate its price to the market. Such a game is a struggle for leadership: if players are informed about each other's preferences, then it turns out to be beneficial to have the first move and force the other player to take the position of the slave [4]. The leader in the procurement of raw materials can be an enterprise that has significant production capacity, cost advantages, and also has a qualified PR-service to collect and process information necessary for the procurement and production.

In the Russian market, purchases of raw materials for the production of secondary precious metals have the greatest impact on the market by 5 large processing enterprises that provide services for the refining of precious metals. Each of them is characterized by significant production capacities and a constant specific cost of produced products, in particular, gold bullion. Scrap as raw material for processing is classified either by the percentage content of gold or by its origin, depending on the sphere of production (in the jewelry industry, electronic, electrochemical, defense, radio industry, domestic waste). The percentage content of valuable components in various types of raw materials is established, and when receiving a specific batch for processing, the plant pays the supplier half of the value of gold contained in this scrap form according to passport data. For products in which there is no data on precious metals, a calculation is made taking into account the number of electronic components. For various types of raw materials, such as transistor glass insulators, printed circuit boards, IBM computers, the scrap of electronic systems of airplanes and tanks, the generalized component composition of mixed scrap of electronic devices, there are equilibrium prices. But the increase in purchasing prices by one enterprise cannot but cause the reaction of other participants. If one of the enterprises has an advantage in costs, then it can become a leader in the industry and increase procurement prices, thereby violating the existing balance. The advantage in costs can be based, for example, on the use of technology for the integrated use of raw materials, that is, extracting from electronic scrap not only gold but also other valuable components, which allows you to obtain additional profits from the sale of precious and non-ferrous metals and their products.

\section{Results}

The models considered allowing us to formalize the behavior of companies on the oligopolistic market and find a solution to the game in conditions of uncertainty. This will make it possible to develop recommendations for making strategic decisions from the point of view of the mathematical theory of games for providing raw materials with the necessary components.

Thus, the proposed rules of game models of non-cooperative interaction and competition are elements of the basis for planning the business processes of the enterprise and the principles of implementing a competitive procurement strategy, on the basis of which it is possible to implement long-term plans for an enterprise to improve the economic state.

\section{References:}

1. A. Gridchina, V. Smolentsev, A. Ksenofontov, E. Nekrasova, I. Skvortsov, V. Mineeva, JABER, 15, 111-121 (2017)

2. A. Maltseva, A. Gridchina, E. Maimina, I. Veselov, Ponte Academic Journal, 73, 5 (2017) 
3. Y. Aleksakhina, S. Novoselov, S. Larina, N. Klimovskikh, E. Gorlova, JABER, 15, 12, 93-101 (2017)

4. 4. N. Novicova, K. Barmuta, V. Kaderova, D. Il'yaschenko, R. Abdulov, A. Aleksakhin, IJEFI, 6, 8S, 65-70, Available at http: www.econjournals.com (2016)

5. A. Anisimov, A. Obukhova, Y. Aleksakhina, A. Zhaglovkaya, A. Kudra, IJEP, 11, 2, 442-448 (2017)

6. A. Gridchina, A. Maltseva, N. Barsukova, T. Kuzmina, JAES, XII, 5 (51), 1531-1548 (2017)

7. Y. Aleksakhina, L. Zimovich, I. Khaibullina, S. Nosova, S. Lyubimtseva, IJEFI, 6, 8S, 148-153 (2016)

8. Y. Aleksakhina, S. Larina, N. Klimovskikh, E. Gorlova, Y. Shedko, JABER, 15, S1, 93-101 (2017)

9. A. Gridchina, O. Grigorenko, D. Klyuchnikov, I. Litvinenko, E. Kolpak, IJEFI, 6, S1, 256-260 (2016)

10. A. Gridchina, A. Maltseva, JAES, XI, 6(44), 1077-1083. (2016)

11. A. Gridchina, L. Orekhova, S. Lyubimtseva, N. Yakovenko, I. Komov, IJEFI, 6, S8, 54-59 (2016)

12. A. Anisimov, Y. Polozhentseva, A. Zhaglovskaya, A. Aleksakhin, Eurasian mining, 2, 53-56 (2017)

13. A. Vasin, V. Morozov, Teoriya igr i modeli matematicheskoy ekonomiki., (MAKS Press, 2005)

14. E. Borel, Econometrica, 21, 1, 97-117, 1953)

15. E. Mulen, Teoriya igr s primerami iz matematicheskoy ekonomiki, (Mir, 1985)

16. V. Glukhov, M. Mednikov, S. Korobko, Matematicheskiye metody i modeli dlya menedzhmenta, (Lan, 2000)

17. S. Avdasheva, N. Rozanova, Teoriya organizatsii otraslevykh rynkov, (Izdatel'stvo Magistr, 1998.)

18. M. Afanas'yev, B. Suvorov, Issledovaniye operatsiy v ekonomike, Ekonomicheskiy fakul'tet MGU, TEIS, 312 (2003) 